\title{
Antimicrobial and anti-biofilm properties of polypropylene meshes coated with metal-containing DLC thin films
}

\author{
Elisa M. Cazalini $\oplus^{1} \cdot$ Walter Miyakawa ${ }^{1} \cdot$ Guilherme R. Teodoro $^{2} \cdot$ \\ Argemiro S. S. Sobrinho ${ }^{1}$. José E. Matieli ${ }^{1} \cdot$ Marcos Massi $^{1,3} \cdot$ Cristiane Y. Koga-Ito $^{2,4}$
}

Received: 7 February 2017 / Accepted: 5 May 2017 / Published online: 17 May 2017

(C) Springer Science+Business Media New York 2017

\begin{abstract}
A promising strategy to reduce nosocomial infections related to prosthetic meshes is the prevention of microbial colonization. To this aim, prosthetic meshes coated with antimicrobial thin films are proposed. Commercial polypropylene meshes were coated with metalcontaining diamond-like carbon (Me-DLC) thin films by the magnetron sputtering technique. Several dissimilar metals (silver, cobalt, indium, tungsten, tin, aluminum, chromium, zinc, manganese, tantalum, and titanium) were tested and compositional analyses of each Me-DLC were performed by Rutherford backscattering spectrometry. Antimicrobial activities of the films against five microbial species (Candida albicans, Escherichia coli, Pseudomonas aeruginosa, Staphylococcus aureus, and Enterococcus faecalis) were also investigated by a modified Kirby-Bauer test. Results showed that films containing silver and cobalt have inhibited the growth of all microbial species. Tungsten-DLC, tinDLC, aluminum-DLC, zinc-DLC, manganese-DLC, and tantalum-DLC inhibited the growth of some strains, while chromium- and titanium-DLC weakly inhibited the growth of only one tested strain. In-DLC film showed no
\end{abstract}

Elisa M. Cazalini

elisa.cazalini@gmail.com

1 Department of Physics, Technological Institute of Aeronautics ITA, São José dos Campos, SP, Brazil

2 Oral Biopathology Graduate Program, Institute of Science and Technology, São Paulo State University - UNESP, São José dos Campos, SP, Brazil

3 School of Engineering-PPGEMN, Mackenzie Presbyterian University, São Paulo, SP, Brazil

4 Department of Environmental Engineering, Institute of Science and Technology, São Paulo State University - UNESP, São José dos Campos, SP, Brazil antimicrobial activity. The effects of tungsten-DLC and cobalt-DLC on Pseudomonas aeruginosa biofilm formation were also assessed. Tungsten-DLC was able to significantly reduce biofilm formation. Overall, the experimental results in the present study have shown new approaches to coating polymeric biomaterials aiming antimicrobial effect.

Graphical Abstract

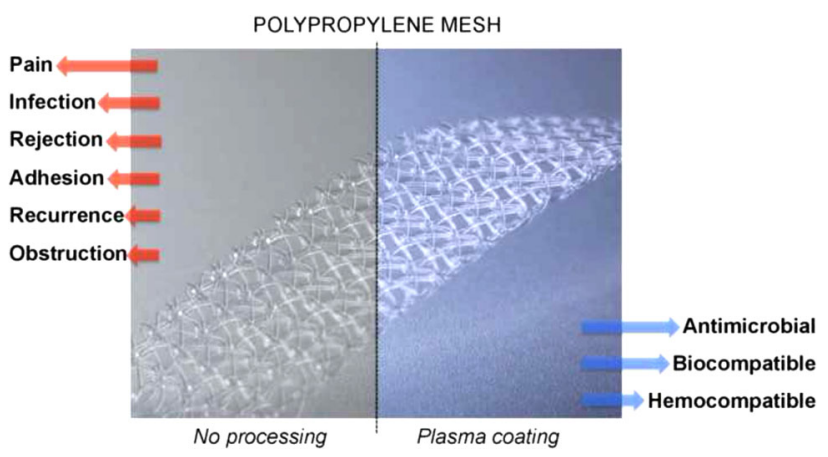

\section{Introduction}

Increase in life expectancy of the world's population has led to a growing tendency to incorporate artificial devices in human body, and to search for high performance biomaterials. Recent studies have focused not only on designing and fabrication, but also on surface modifications of these devices, aiming to improve their performance [1].

Cold plasma deposition is cost-effective and modifies the surface features by coating with a thin film. The process 
does not cause modifications in the physical and mechanical properties of the bulk material [2]. Plasma-based deposition has promising applications in the biomedical field. According to Cloutier et al. [3], this methodology combines "easy preparation, great versatility, economical and solventfree processing, compositional control, conformal and pinhole-free coverage, no thermodynamic constraints, sterility upon preparation, and the possibility for commercial-scale deposition."

Plasma coatings with nanostructured or nanoparticlesimplanted thin films can induce additional characteristics to the material. Much beyond surface topography and morphology, other useful properties such as the antimicrobial effect can be achieved. Also, increased wear and corrosion resistance, higher durability, and long-term stability in biological environments can be obtained [3]. All these properties are of unquestionable relevance in a material for medical applications.

Diamond-like carbon (DLC) coatings are commonly used in biomedical field due to their bio- and hemocompatibility, low surface friction, wear resistance, and chemical inertness [1, 4]. However, increased performance of multifunctional and bioactive surfaces can be also achieved by incorporating appropriate elements [1-6].

Metallic dopants have been historically employed as disinfectants and antimicrobial agents [7]. Structured in thin films as nanoparticles, oxides, or complex nanocomposites; the coated materials exhibit unique optical, electrical, and catalytic properties. Due to these characteristics, they have become very important in medical areas, for water disinfection, and for food and textile industries [8].

Polypropylene is widely used in medicine, as nonabsorbable synthetic suture material, surgical meshes, catheters, syringes, filters, containers, bags, drug-delivery systems, and others [9]. However, in spite of this continuous dissemination of application, medical polypropylene is far from ideal. According to the literature, prosthetic meshes for hernia repair may cause infections in about $8 \%$ of the cases, with physical and psychological consequences to the patients [10]. Notwithstanding, prosthetic meshes have been widely used as urinary incontinence slings [11], pelvic organ prolapse suspender [12], and skin tissue carrier [13]. For these reasons, permanent investigation and development of safer bioengineered synthetic meshes are absolutely necessary.

Besides of antimicrobial activity, the anti-biofilm property has been considered highly desirable for biomaterials. In fact, bacterial biofilms are more resistant to antibiotics at concentrations thousand-fold greater when compared to free cells in suspension [14]. For this reason, recent studies focused efforts on prevention of biofilm formation [15-17]. Bacterial biofilms are commonly found in nature, being formed by colonies adhered to biotic or abiotic surfaces representing a reservoir of bacteria that can be shed to the body, leading to chronic infections [18]. Infections caused by microbial biofilms are a significant socio-economic burden that implicates hospitalization, patient suffering and reduced life quality [19].

The aim of this study was to investigate the antimicrobial and anti-biofilm potentials of commercial polypropylene meshes coated with several dissimilar metal-containing DLC (Me-DLC) thin films by the magnetron sputtering technique.

\section{Materials and methods}

\subsection{Materials}

Standard commercial prosthetic meshes (Intracorp ${ }^{\circledR}$ ) for hernia repair, polypropylene disks and silicon wafers were used as substrates. Carbon and high purity metals from Kurt J. Lesker Company listed in Table 1 were used in the metalcontaining DLC (Me-DLC) thin film deposition.

\subsection{Deposition and characterization of Me-DLC thin films}

A dual magnetron sputtering plasma system was used for deposition of the thin films, whereby two solid 4" diskstargets, one of carbon and other of a metal are bombarded by plasma ions. The ejected sputtering material of each target hits the substrate, forming a thin film coating. Parameters of the plasma process were gathered in Table 2. Care was taken to keep these parameters strictly constant to each deposition, so as the process is highly reproducible and accurately controlled. Obviously, the percentage of metal inserted in each film will vary according to the target sputter yield [20]. The distinct metallic disk-targets are bombarded

Table 1 Targets and respective purity level

\begin{tabular}{ll}
\hline Target & Purity level \\
\hline Carbon (C) & $99.99 \%$ \\
Titanium (Ti) & $99.95 \%$ \\
Tantalum (Ta) & $99.95 \%$ \\
Chromium (Cr) & $99.95 \%$ \\
Tungsten (W) & $99.95 \%$ \\
Manganese (Mn) & $99.95 \%$ \\
Cobalt (Co) & $99.99 \%$ \\
Silver (Ag) & $99.99 \%$ \\
Zinc (Zn) & $99.99 \%$ \\
Aluminum (Al) & $99.99 \%$ \\
Indium (In) & $99.99 \%$ \\
Tin (Sn) & $99.99 \%$ \\
\hline
\end{tabular}


Table 2 Parameters of the deposition process

\begin{tabular}{ll}
\hline Parameter & Value \\
\hline Argon pressure & $3.0 \mathrm{mTorr}$ \\
Argon flow & $10 \mathrm{sccm}$ \\
DC power applied on C target & $300 \mathrm{~W}$ \\
DC power applied on metals target & $5 \mathrm{~W}$ \\
Time & $5 \mathrm{~min}$ \\
\hline
\end{tabular}

by plasma ions with the same energy, as the power applied on metals targets were fixed at $5 \mathrm{~W}$, consequently, the number of ejected atoms will be proportionally different, according to their binding energies.

The depositions were performed on three substrates: prosthetic polypropylene meshes and polypropylene disks, for microbiological analyses; and silicon wafers, for chemical characterizations. Fig 1 shows the schematic for the coating of substrates by dual magnetron sputtering plasma system. Surface microstructures of coated and uncoated prosthetic meshes were evaluated by scanning electron microscopy-SEM (Vega3 XMU, TESCAN ORSAY HOLDING, a.s.), and the compositional contents of MeDLC thin films on silicon wafers were evaluated by Rutherford backscattering spectrometry-RBS, in a multianalyses chamber with a tandem Pelletron electrostatic accelerator (5SDH, NEC Corporation) in association with SIMNRA, a shareware program developed by Matej Mayer, at the Max-Planck-Institut für Plasmaphysik (Garching, Germany) for spectra simulation.

\subsection{Antimicrobial activity of Me-DLC coated polypropylene meshes}

Reference strains Candida albicans ATCC 18804, Escherichia coli ATCC 23922, Pseudomonas aeruginosa ATCC 15442, Staphylococcus aureus ATCC 6539 and Enterococcus faecalis ATCC 29212 were used for testing the antimicrobial activity of the materials. The strains were kept in glycerol-BHI (brain and heart infusion) broth at $-80^{\circ} \mathrm{C}$, and prior the experiments they were plated on $\mathrm{BHI}$ agar slants. The plates were then kept at $37^{\circ} \mathrm{C}$ for $24 \mathrm{~h}$. Tests were performed in triplicate.

Standardized microbial suspensions at $0.5 \mathrm{McF}$ arland scale were prepared in sterile saline solution $(0.9 \% \mathrm{NaCl})$ for each strain. A modified Kirby-Bauer test was performed using $6 \mathrm{~mm}$ diameter of Me-DLC coated polypropylene meshes [21]. After $48 \mathrm{~h}$ of incubation, the presence of an inhibition halo was observed and measured, as indicative of the antimicrobial activity of the Me-DLC coating. The specimens were sterilized by $20 \mathrm{kGy}$ gamma radiation, and

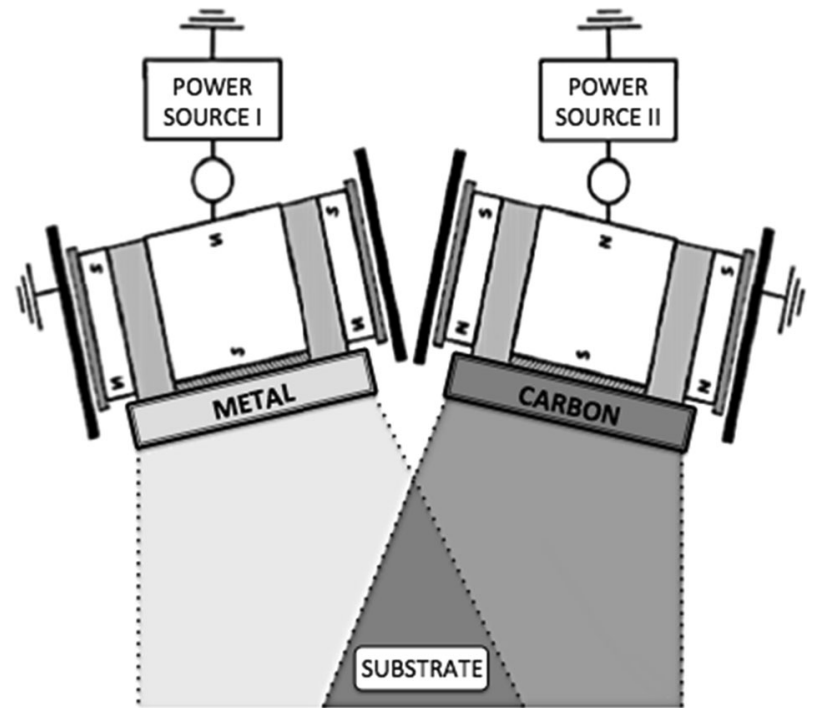

Fig. 1 Schematic view of the dual magnetron deposition system using carbon and metal pure targets

specimens without coating were included as negative control.

\subsection{Effect of Me-DLC coating on $P$. aeruginosa biofilm formation}

The antimicrobial activity of silver is already widely known. For this reason, the two coatings with higher antimicrobial effect (excluding silver) were selected for the evaluation of anti-biofilm activity. Thus, the experiment was carried out with biofilms in samples of thin films synthesized with tungsten (W-DLC) and cobalt (Co-DLC). Pseudomonas aeruginosa showed the lowest susceptibility to Me-DLC films and, for this reason, it was chosen for these tests.

$P$. aeruginosa ATCC 15442 was cultured in brain hear infusion agar (BHI) for $24 \mathrm{~h}$ at $37^{\circ} \mathrm{C}$. After, a standardized suspension containing $10^{7}$ cells $/ \mathrm{ml}$ was obtained in phosphate buffered saline (PBS, $\mathrm{pH}$ 6.5) with the aid of a spectrophotometer. This suspension was further diluted 1:10 in BHI broth for preparing the final inoculum.

An aliquot of $3 \mathrm{ml}$ was transferred into a 24 well plate containing sterile polypropylene disks specimens and $3 \mathrm{ml}$ of BHI broth. The specimens were sterilized by $20 \mathrm{kGy}$ gamma radiation.

The plate was incubated at $37^{\circ} \mathrm{C}$ for $90 \mathrm{~min}$ for preadhesion of the microbial cells. After, they were washed with $1 \mathrm{ml}$ of PBS and transferred to new wells with $3 \mathrm{ml}$ of BHI broth and incubated for $24 \mathrm{~h}$ at $37^{\circ} \mathrm{C}$. After $24 \mathrm{~h}$, the specimens were washed once more and the culture medium was refreshed. After incubation for $24 \mathrm{~h}$ at $37^{\circ} \mathrm{C}, 48 \mathrm{~h}$ biofilm was obtained. 
Then, the biofilm formed on the specimens were gently washed with PBS and sonicated on ice for $30 \mathrm{~s}$ in PBS. Initial suspensions were diluted in PBS and plated on $\mathrm{BHI}$ agar to obtain the number of colony forming units per specimen (CFU/specimen). Uncoated polypropylene samples were used as negative control.

\subsection{Analyses of results}

The results obtained for the effects of coatings on $P$. aeruginosa biofilm formation were statistically compared. Values of colony forming units per specimen (CFU/specimen) in the groups tungsten (W-DLC), cobalt (Co-DLC) and control (uncoated) were compared by ANOVA and Dunnett's post hoc test. The level of significance was set as $5 \%$.

\section{Results}

\subsection{Material characterization}

SEM was performed on coated and uncoated prosthetic meshes, and their scanning electron micrographs are shown in Fig 2. The uncoated mesh fibers presented homogeneous surface with typical manufacturing grooves (Fig. 2a). It also can be clearly seen that in all coated meshes (Figs. 2b-1), the deposited thin film did not cover the fiber manufacturing grooves. However, some contrasting microstructures were observed. In Figs. 2e (W-DLC), $2 \mathrm{f}$ (Cr-DLC), $2 \mathrm{i}$ (Sn-DLC) and 21 (In-DLC), vermicular or worm-shaped microstructures were formed on the surface. On the other hand, in Ti-DLC (Fig. 2b), Mn-DLC (Fig. 2d), Al-DLC (Fig. 2g), Co-DLC (Fig. 2h), Ag-DLC (Fig. 2j), and Zn-DLC (Fig. 2k) coated fiber surfaces, only nanometer-sized grains, probably clusters are viewed. The exception was the Ta-DLC coated fiber (Fig. 2c), which exhibited both: grains and vermicular microstructures.

\subsection{Me-DLC compositional contents by RBS}

Obtained elemental contents of Me-DLC coatings are presented in Table 3. Expected variations in metal percentages were observed, as differences in binding energies lead to distinct sputter yields.

\subsection{Me-DLC coated polypropylene meshes antimicrobial activity}

The antimicrobial effect of each metal-doped coating against the microbial species is summarized in Table 4. These effects were estimated by the values of diffusion halos around the specimens and the microbial growth over the fibers of meshes. It is important to observe that in conventional Kirby-Bauer protocol, the paper disk is impregnated with a liquid antibiotic. This disk is placed on the agar plate and the antibiotic begins to diffuse into the surrounding agar. That is why this method is also called Kirby-Bauer diffusion test. In our modified Kirby-Bauer test, Me-DLC coated polypropylene mesh disks were used. The Me-DLC thin film is solid and firmely fixed on the mesh surface; hence the thin film cannot diffuse into the agar. In our analyses, we set the Ag-DLC halo of $8.0 \mathrm{~mm}$ as the inhibition bias $(\mathrm{H})$. Halos lower than $8.0 \mathrm{~mm}$ mean intermediate inhibition (I). (F) means no inhibition halo with no microbial growth on mesh fibers surface, and $(\mathrm{N})$ refers to no inhibition halo and microbial growing over the mesh. Our results cannot be compared with conventional Kirby-Bauer protocol results by any means.

Ag-DLC showed inhibition with halos $\geq 8.0 \mathrm{~mm}$ for all the tested microbial species. Co-DLC also had inhibitory effects on all the species. Tungsten-DLC, tin-DLC, aluminum-DLC, zinc-DLC, manganese-DLC, tantalum-DLC inhibited the growth of some strains, while chromiumDLC and titanium-DLC did not show inhibition halos against any strain. In-DLC film showed no inhibition activity.

\subsection{Effect of Me-DLC coating on $P$. aeruginosa biofilm formation}

$P$. aeruginosa biofilm formation varied among the groups (ANOVA, $p=0.0003$ ) and are shown in Fig. 3. Results were expressed by the number of $\mathrm{CFU} /$ specimen. The mean values and standard deviation of $\mathrm{CFU} /$ specimen in the group cobalt-containing DLC (Co-DLC) was 73.16士 25.51. For group tungsten-containing DLC (W-DLC) this value was $16.16 \pm 10.32$. Uncoated control group showed $77.33 \pm 15.69$.

Data analyses showed that W-DLC film was able to significantly reduce the biofilm formation in relation to control $(p<0.05)$. Conversely, biofilm formation in the surface of Co-DLC was similar in relation to control ( $p=$ 0.964).

\section{Discussion}

The importance of this work relies on the innovative proposal of metal-containing thin film deposition over meshes (bundle of soft polypropylene fibers) aiming to contribute to reduction in postoperative microbial infections.

In addition to deposition parameters, the metal content is a relevant issue in Me-DLC thin films, because metallic components are usually grouped in small metallic or metalcarbide clusters (nanometer-sized grains). According to 


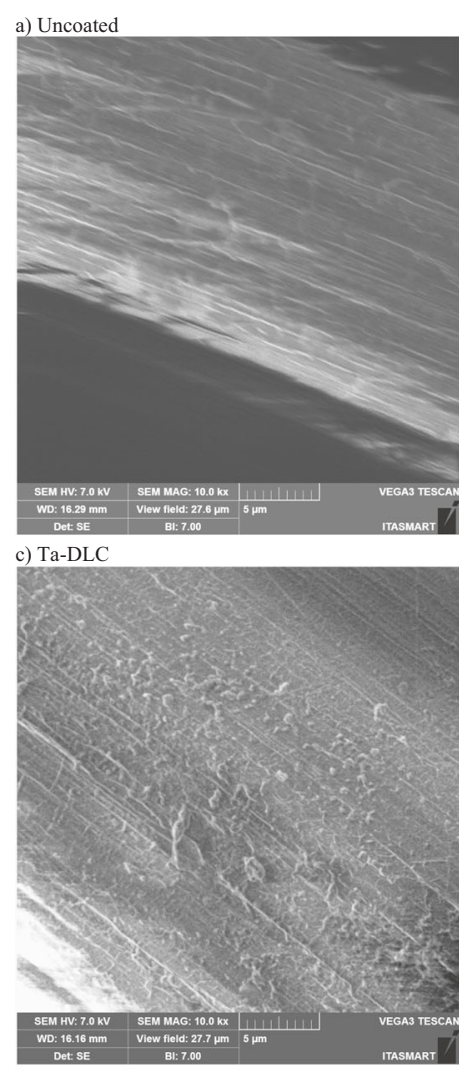

b) Ti-DLC
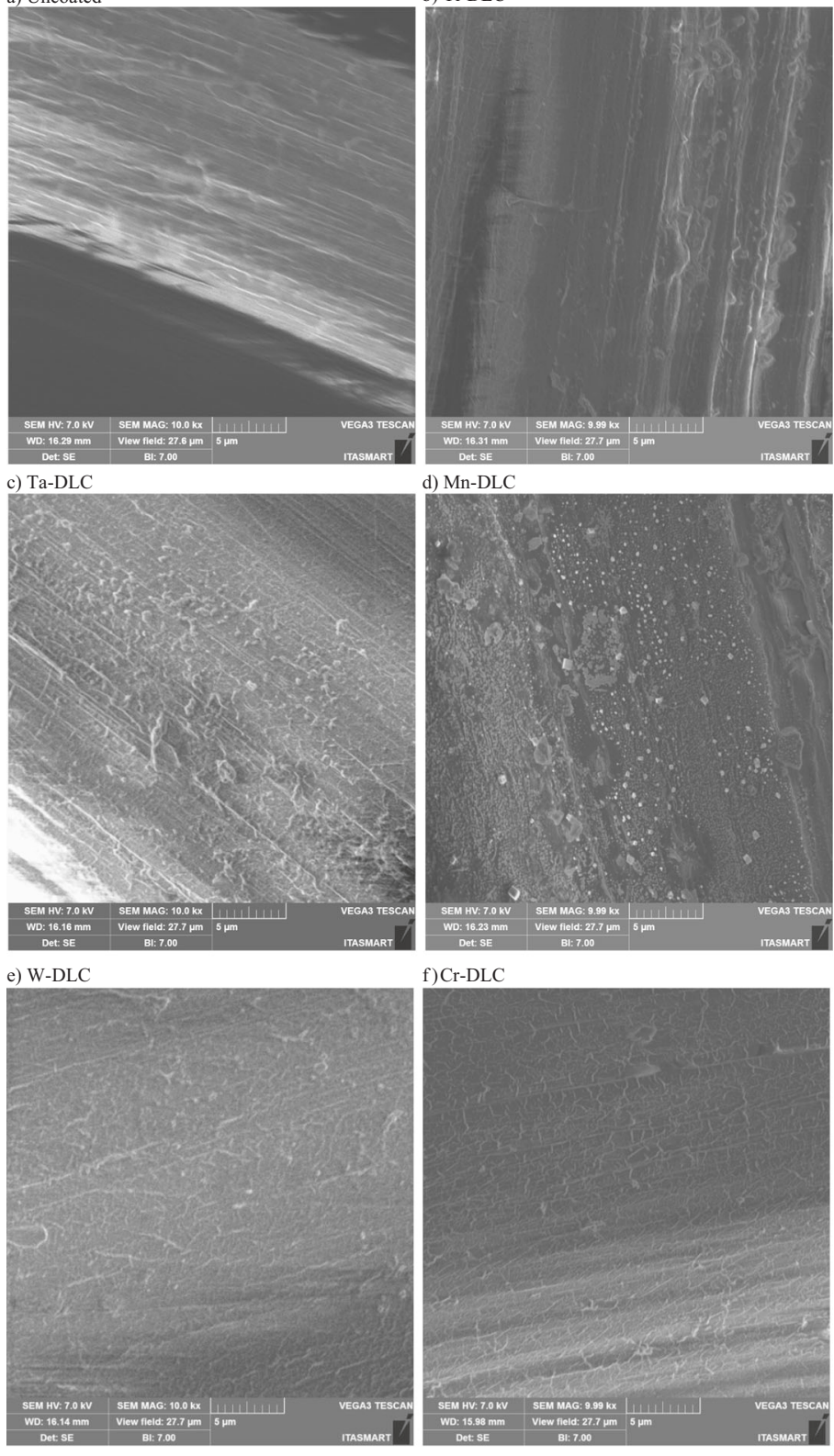

f)Cr-DLC
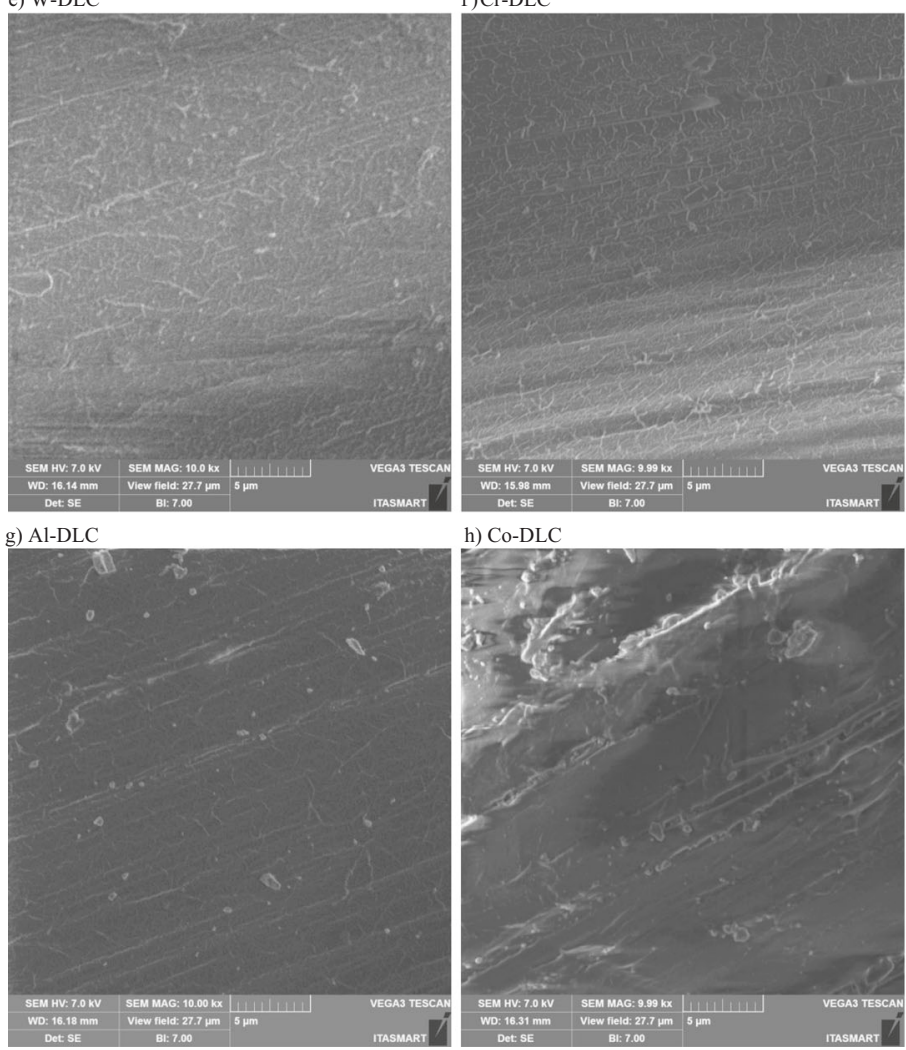

h) $\mathrm{Co}-\mathrm{DLC}$

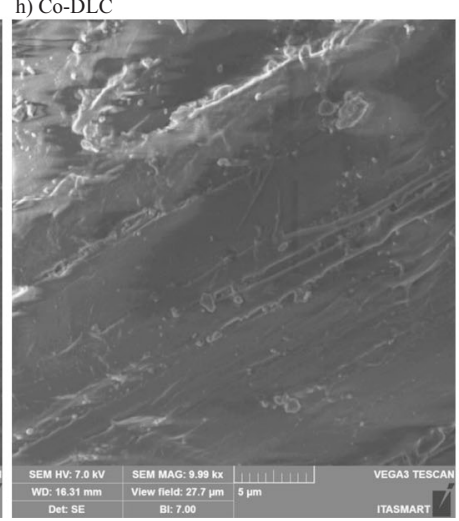

Fig. 2 Scanning electron micrographs of uncoated mesh a, and coated with Ti-DLC b, Ta-DLC c, Mn-DLC d, W-DLC e, Cr-DLC f, Al-DLC $\mathbf{g}$, Co-DLC h, Sn-DLC i, Ag-DLC j, Zn-DLC k, and In-DLC I thin film 


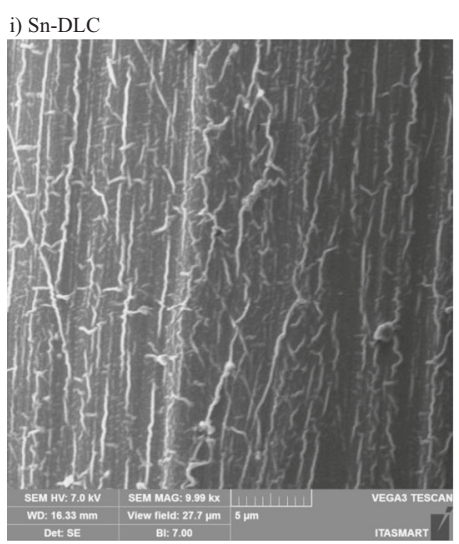

j) Ag-DLC
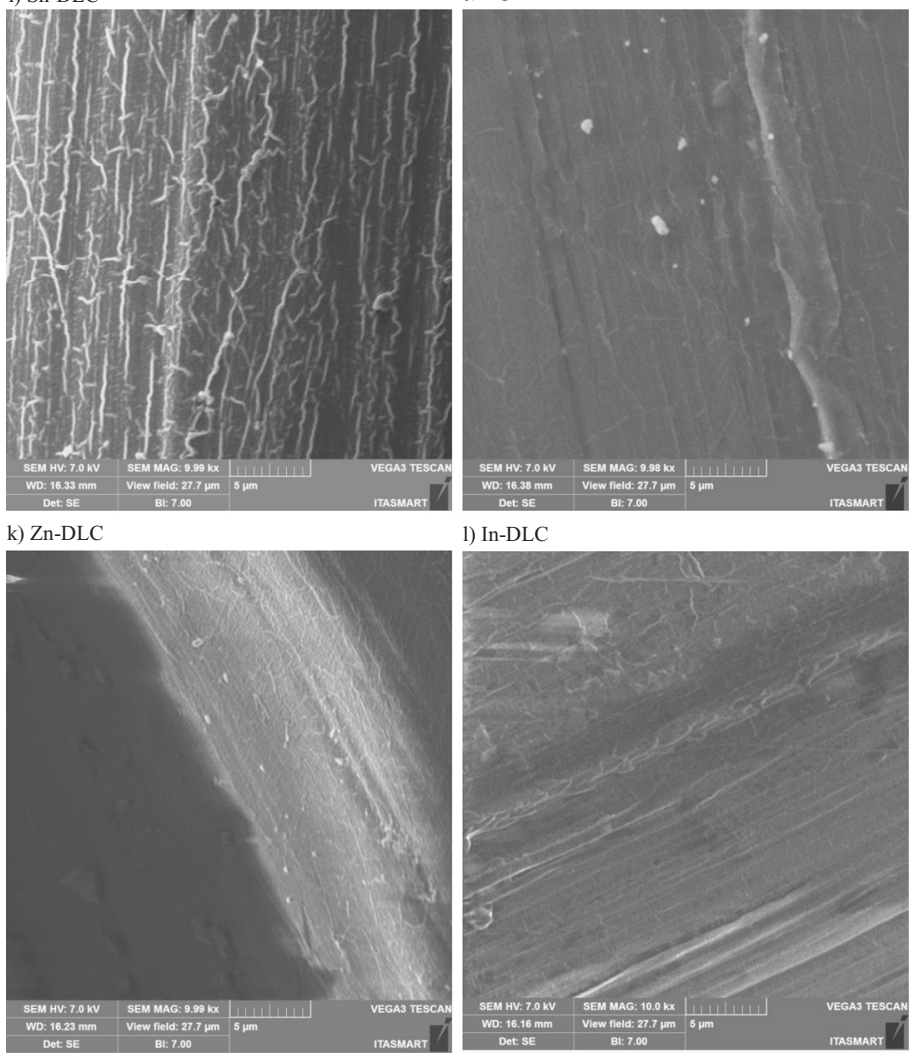

1) In-DLC

Fig. 2 Continued

Table 3 Elemental composition and contents obtained from RBS analyses

\begin{tabular}{lcr}
\hline Coating & $\% \mathrm{Me}$ & $\% \mathrm{C}$ \\
\hline None & 0.0 & 100.0 \\
Ti-DLC & 1.0 & 99.0 \\
Ta-DLC & 1.0 & 99.0 \\
Mn-DLC & 1.6 & 98.4 \\
W-DLC & 2.0 & 98.0 \\
Cr-DLC & 2.4 & 97.6 \\
Al-DLC & 5.0 & 95.0 \\
Co-DLC & 5.7 & 94.3 \\
Sn-DLC & 8.0 & 92.0 \\
Ag-DLC & 9.0 & 91.0 \\
Zn-DLC & 10.0 & 90.0 \\
In-DLC & 22.0 & 78.0 \\
\hline
\end{tabular}

several authors [22-26], dimensions and distances between grains are also dependent on metal concentration, and dispersed metal-carbide particles in the DLC matrix usually come from low metal contents. Actually, this rule was seen in our SEM micrographs, except for the Mn-DLC thin film (Fig. 2d). Even at concentrations as low as $1.6 \%$,
Table 4 Antimicrobial activity of coated and uncoated polypropylene meshes ( $N=$ no inhibition halo with microbial growth on mesh fibers; $F=$ no inhibition halo and no microbial growth on mesh fibers surface; $I=$ intermediate inhibition halo $\leq 8.0 \mathrm{~mm}$; and $H=$ inhibition halo $\geq$ $8.0 \mathrm{~mm})$

\begin{tabular}{lccccc}
\hline Coating & $\begin{array}{c}\text { C. albicans } \\
\text { ATCC } 1884\end{array}$ & $\begin{array}{c}\text { E. coli } \\
\text { ATCC } 23922\end{array}$ & $\begin{array}{c}\text { E. faecalis } \\
\text { ATCC 29212 }\end{array}$ & $\begin{array}{c}\text { S. aureus } \\
\text { ATCC } 6539\end{array}$ & $\begin{array}{c}\text { P. aeruginosa } \\
\text { ATCC 15442 }\end{array}$ \\
\hline $\begin{array}{l}\text { None } \\
\text { (negative control) }\end{array}$ & $\mathrm{N}$ & $\mathrm{N}$ & $\mathrm{N}$ & $\mathrm{N}$ & $\mathrm{N}$ \\
Ag-DLC & $\mathrm{H}$ & $\mathrm{H}$ & $\mathrm{H}$ & $\mathrm{H}$ & $\mathrm{H}$ \\
Co-DLC & $\mathrm{I}$ & $\mathrm{I}$ & $\mathrm{I}$ & $\mathrm{I}$ & $\mathrm{I}$ \\
W-DLC & $\mathrm{I}$ & $\mathrm{I}$ & $\mathrm{F}$ & $\mathrm{N}$ & $\mathrm{I}$ \\
Al-DLC & $\mathrm{N}$ & $\mathrm{F}$ & $\mathrm{N}$ & $\mathrm{I}$ & $\mathrm{I}$ \\
Sn-DLC & $\mathrm{I}$ & $\mathrm{N}$ & $\mathrm{I}$ & $\mathrm{N}$ & $\mathrm{N}$ \\
Zn-DLC & $\mathrm{I}$ & $\mathrm{N}$ & $\mathrm{F}$ & $\mathrm{N}$ & $\mathrm{N}$ \\
Mn-DLC & $\mathrm{N}$ & $\mathrm{I}$ & $\mathrm{F}$ & $\mathrm{N}$ & $\mathrm{N}$ \\
Ta-DLC & $\mathrm{H}$ & $\mathrm{N}$ & $\mathrm{N}$ & $\mathrm{F}$ & $\mathrm{N}$ \\
Cr-DLC & $\mathrm{F}$ & $\mathrm{N}$ & $\mathrm{N}$ & $\mathrm{N}$ & $\mathrm{N}$ \\
Ti-DLC & $\mathrm{N}$ & $\mathrm{F}$ & $\mathrm{N}$ & $\mathrm{N}$ & $\mathrm{N}$ \\
In-DLC & $\mathrm{N}$ & $\mathrm{N}$ & $\mathrm{N}$ & $\mathrm{N}$ & $\mathrm{N}$ \\
\hline
\end{tabular}

the fiber surface presented great amount of non-dispersed nanograins.

Transition metals of group IV to VI generally form metal-carbide phases in the DLC matrix [27], and carbidebonding is also concentration dependent. Tungstencarbide phase is not formed at concentrations lower than 


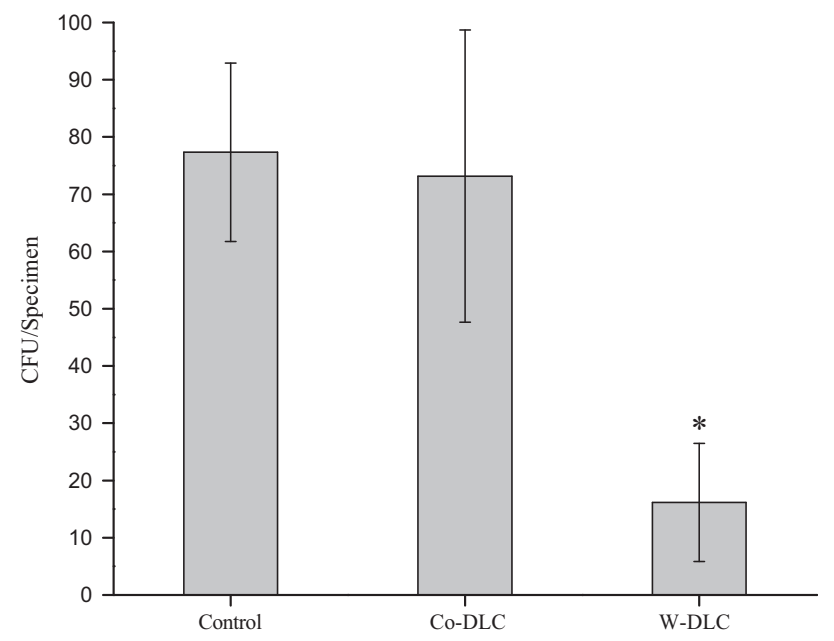

Fig. 3 Inhibition of Pseudomonas aeruginosa biofilm formation by plasma coating polymers; histograms represent means and standard deviations. * statistically significant difference in relation to control $(p<0.05)$

2.8 at $\%$, but amorphous and crystalline tungsten-carbide are formed at concentrations higher than 2.8 at $\%$ and 3.6 at $\%$, respectively [24]. Furthermore, still according to Bewilogua et al. [27], metal-carbide particles may not be so strongly cross-linked with the surrounding amorphous carbon network, and can react more readily with the oxygen.

On the other hand, while aluminum carbide is commercially supplied by the market, according to Dai and Wang [23], aluminum does not form carbide when incorporated into DLC films.

From the SEM micrographs and Table 3, it can be inferred that, on the one hand, in titanium-DLC, aluminumDLC, cobalt-DLC, silver-DLC, and zinc-containing DLC films, carbides were not formed and larger metallic clusters were sparse and homogeneously dispersed at the surface, and most probably, in the DLC matrix. On the other, in tungsten- and chromium-containing DLC films, metallic and metal-carbide nanograins were possibly embedded into the DLC matrix bulk.

As well pointed by Dai and Wang [23], the comprehensive understanding of metal-containing DLC coatings was still not fully established owing not only to the complexity of carbon hybridized bonds, particularly at low metal contents, but to the diversity of metal nature, and to the variety of deposition techniques as well.

The antimicrobial response of Me-DLC coated polypropylene meshes, the inhibition halo, if any, was observed only very close to the mesh disk area, suggesting a local passive mechanism of action, and no diffusion of metals. The Me-DLC thin film is solid and strongly fastened on the mesh surface; hence the thin film could not diffuse into the agar. This is an interesting finding, considering that the spread of metals to the environment would be negative for biomedical applications. Future studies on the cyto and genotoxicity of these materials to human cells are still needed.

Predictably, the Ag-DLC coated polypropylene mesh has exhibited the highest antimicrobial activity against all tested microorganisms, with inhibiting halo around $8.0 \mathrm{~mm}$ diameter. Silver has been used since ancient times [28] and is currently the most used antimicrobial metal [29]. Its toxic effect is well-known [30-32], and Das et al. [30] reported that carboxymethylcellulose gel containing silver nanoparticles had been effective against the growth of methicillin-resistant S. aureus (ATCC 6538), E. coli (ATCC 8739) and $P$. aeruginosa (ATCC 9027), even at concentrations as low as $50 \mathrm{ppm}$. In Ag-DLC coatings, silver is grouped in nanometer-sized clusters, which are dispersed in the Ag-DLC matrix [22], and in the fiber surface, as well (Fig. 2j). Hence, we believe that the antimicrobial effect of the Ag-DLC coated mesh should probably be due to these nanograins on the thin film surface.

On the contrary, indium-containing DLC coated mesh did not have any observable antimicrobial action, even at appreciable contents as $22 \%$. However, some bacteriostatic activity of $\mathrm{In}^{3+}$ ion had been observed when chelated (attached to an anion group with two or more coordination sites) to a siderophore (iron-binding protein) [28]. According to the literature, this heavy metal ion mimics the $\mathrm{Fe}^{3+}$ in the protein, but does not replace its function in the cell metabolism, acting as a toxic substance. In our In-DLC coated mesh, vermicular formation tendency was noted in Fig. 21, suggesting that metallic-indium clusters should be embedded into the DLC matrix bulk, as observed with other high content Me-DLC films [33]. Indium-carbide cannot be found in In-DLC film, as it is gaseous at ambient temperature [34]. Hence, the tested microorganisms could not uptake $\mathrm{In}^{3+}$ ions from the DLC matrix to their metabolism, and probably, metallic-indium clusters were so embedded into the DLC matrix that microbial cells have grown over the In-DLC coated mesh fibers. Despite the low cobalt content in the thin film, and the sparse nanosized-grains distributed on the mesh fiber surface (Fig. 2h), the Co-DLC coated polypropylene mesh showed the second most intense antimicrobial activity. Actually, some authors had also observed cobalt antimicrobial activity, as cobalt complexes [35-38]. Although the antimicrobial mechanism of cobalt is still not fully elucidated, care should be taken as metal complexes effects on microorganisms are far different, compared with both the pure metal and the metal in the DLC coatings.

On the other hand, Icgen and Yilmaz [39] published an interesting work on the resistance of isolates from a Turkish river to heavy metals and antibiotic drugs. Due to effluents contaminated with antibiotics and heavy metals, 
microorganisms from this river are becoming drug-resistant and with enhanced heavy metal resistance as well. Notwithstanding, isolates exhibited the least resistance against cobalt: only $4 \%$, corroborating our results.

Tungsten-containing DLC coating showed activity against $C$. albicans, E. coli, E. faecalis and P. aeruginosa strains, but not against $S$. aureus. Considering the very low tungsten content in our W-DLC coating, probably tungstencarbide clusters should have not been formed, and even metallic nanoparticles in the coating surface were not observed in our SEM micrographs (Fig. 2e). Lemire et al. [28] stated that metals, including tungsten, are either coordinated by organic compounds or present as water-soluble oxyanion species in the environment. On the other hand, some authors had also related poor or no antimicrobial activity of $\mathrm{WO}_{3}$ nanoparticles against peri-implantitis bacteria [40], and even tungsten oxyanion $\left(\mathrm{WO}_{4}{ }^{2-}\right)$ had presented no significant toxicity against $E$. coli (JM 109), S. aureus (ATCC 29213), and P. aeruginosa (ATCC 27853) [7], emphasizing the low antimicrobial effectiveness of tungsten. Interestingly, tungsten containing DLC coating has shown promising anti-biofilm formation effect. This effect was not reported before and deeper investigation of the mechanism of action is needed. Besides, recent evidences of tungsten toxicity for human cells have been reported [41]. For this reason, the minimal effective concentration necessary for microbial biofilm inhibition and the potential liberation of tungsten for human tissues have still to be determined before suggesting an application of our findings. Notwithstanding, the promising effect of W-DLC coatings can be useful for the development of several materials with antifouling properties.

Both tin- $(\mathrm{Sn})$ and aluminum- (Al) containing DLC coatings had antimicrobial action against some of the microorganisms studied, the first one against $C$. albicans, and E. faecalis, and the second, against $S$. aureus, $P$. aeruginosa and E. Coli. Icgen and Yilmaz have showed that $67 \%$ of isolates were resistant to tin, and $79 \%$ to aluminum [39]. In other recent publication, $\mathrm{SnO}_{2} / \mathrm{SnS}_{2}$ nanocomposites have shown more effectiveness against $E$. coli (ATCC 25922) and $S$. aureus (ATCC 6538) than $\mathrm{SnO}_{2}$ and $\mathrm{SnS}_{2}$ nanoparticles. Nanocrystalline $\mathrm{SnO}_{2}$ thin films deposited by sol-gel exhibited antibacterial activity against $E$. coli and Bacillus spp. [42] as well. Fakhri et al. [43] also had reported antifungal activity of $\mathrm{SnO}_{2}$ and $\mathrm{SnS}_{2}$ nanoparticles, and $\mathrm{SnO}_{2} / \mathrm{SnS}_{2}$ nanocomposites against $C$. albicans. In contrast, in our SEM micrographs (Fig. 2i), nanoparticles were not present in the fiber surface. Concerning aluminum, fresh report [44] demonstrated that aluminum oxide $\left(\mathrm{AlO}_{3}\right)$ nanoparticles had showed concentration dependent inhibition of $E$. coli growing, probably by generating reactive oxygen species, in Fig. 2g sparse nanosized-grains can be viewed. Care should be taken, as DLC films containing incorporated metals are far different from pure metals, metal-oxides $\left(\mathrm{SnO}_{2}, \mathrm{AlO}_{3}\right)$ and metal-compounds $\left(\mathrm{SnS}_{2}\right)$.

Chromium-containing DLC and zinc-containing DLC coatings have both revealed antifungal potential against $C$. albicans. According to Páez et al. [45], some chromium complexes can produce DNA damage and may show antibacterial and antifungal activity. However, metal complexes toxicity depends on the coordinated ligand. Han et al. [46] demonstrated that chromium-carbide is formed at the filmsubstrate interface when the $\mathrm{Cr}^{+}$ion is implanted on DLC films deposited by magnetron sputtering over silicon substrate. This might have happened with our Cr-DLC coating as well (Fig. 2f). On the other hand, Jenilek et al. [47] also tested antimicrobial activities of Cr-DLC for implants, prepared by laser-magnetron deposition. These authors have coated silicon, $\mathrm{Ti}_{6} \mathrm{Al}_{4} \mathrm{~V}$ and CoCrMo substrates with DLC and Cr-DLC layers. Despite differences in the deposition technique and in the film characteristics compared with ours, they did not observe antibacterial effects against $S$. aureus and $P$. aeruginosa. Concerning zinc, Pop et al. [44] reported that zinc ions exhibit bacteriostatic effect, by inhibiting different physiological pathways, while $\mathrm{ZnO}$ has antimicrobial effect by oxidative stress. And Singh et al. [48] reported that zinc-complexes had exhibited the highest antimicrobial activity against Pseudomonas aeruginosa, Bacillus subtilis, Escherichia coli, and Staphylococcus aureus, and the highest antifungal properties against Aspergillus niger, and Aspergillus flavus.

Manganese-containing DLC film exhibited moderated antimicrobial activity against $E$. coli and E. faecalis. Some authors have reported antibacterial and antifungal activities of Mn(II)-complexes [14, 49] and Mn(III)-complex [50]. However, to the best of our knowledge, characterizations and antimicrobial activities of Mn-DLC were not found in the literature.

Tantalum and titanium are both well-known highly biocompatible and corrosion resistant metals [51]. To the best of our knowledge, no antimicrobial effect has been attributed to pure Ta and Ti metals. Tsai et al. [52] have reported that in the DLC matrix, crystalline $\beta$-Ta and a small fraction of tantalum-carbide is formed, resulting in high biocompatibility with WS1 human fetal skin fibroblast cells. In our antimicrobial test, the Ta-DLC coated mesh revealed some antifungal activity against $C$. albicans. This is a promising outcome, as C. albicans is one of the most common causes of nosocomial infections, and the Ta-DLC coated mesh should associate high biocompatibility with antifungal effect. Evidently, more studies should be conducted to attest this finding.

Ti-DLC coated meshes have prevented growth of E. coli on material surface. Antimicrobial properties of titanium dioxide had been observed when irradiated by ultraviolet light at appropriate wavelengths [44], or when $\mathrm{TiO}_{2}$ 
nanoparticles at specific dimensions, concentration, and zeta potentials are used. But, according to the literature [53], at low concentrations (less than $7-13 \%$ ), Ti atoms are dispersed in the DLC matrix, and at higher concentrations, Ti$\mathrm{C}$ nanoparticles are formed, but no $\mathrm{TiO}_{2}$ was observed at all. In our Ti-DLC thin film, the low titanium concentration $(1 \%)$ and the rare grains in the fiber surface (Fig. 2b) could not explain the antimicrobial effect.

In conclusion, this screening was able to detect promising Me-DLC coatings for both medical and non-medical applications. The clinical use of the materials still depends on additional studies, in particular related to biocompatibility.

\section{Conclusion}

This study showed that silver and cobalt in Me-DLC coated meshes have exhibited inhibition of growth of all tested strains. In opposition, In-DLC thin film was not effective against any strain. Tungsten-, tin- and aluminum-, zinc-, manganese-, tantalum-containing DLC coated meshes inhibited the growth of some strains, while chromium and titanium DLC film weakly inhibited the growth of only one of the tested strains.

From the compositional analyses, it was concluded that at higher metal concentrations ( $>5 \%)$, no metal-carbides were formed and larger metallic clusters were sparse and homogeneously dispersed in the DLC matrix. At low concentrations, metallic and metal-carbide nanograins were homogeneously distributed in the DLC matrix. Inhibition halos were observed only very close to the mesh disk area, suggesting that there was not material diffusion at all. Tungsten-containing DLC was able to inhibit $P$. aeruginosa biofilm.

We concluded that metal-containing DLC coatings did not deliver any antibacterial or antifungal agents, opening up approach possibilities, with combination of two or more distinct metals inserted in the DLC matrix, in order to affect higher number of microbial species.

Acknowledgements The authors are grateful to the Laboratory of Analysis of Materials by Ionic Beams of the Institute of PhysicsUniversity of São Paulo for RBS analysis, Center for Radiation Technology of the Nuclear and Energy Research Institute for the sterilization of the samples, and the agencies Coordination for the Improvement of Higher Education Personnel and National Council for Scientific and Technological Development for the financial support.

\section{Compliance with ethical standards}

Conflict of interest The authors declare that they have no competing interests.

\section{References}

1. Love CA, Cook RB, Harvey T, Dearnley P, Wood R. Diamond like carbon coatings for potential application in biological implants-a review. Tribol Int. 2013;63:141-50.

2. Chu PK, Chen JY, Wang LP, Huang N. Plasma-surface modification of biomaterials. Mater Sci Eng. 2002;36:143-206.

3. Cloutier M, Mantovani D, Rosei F. Antibacterial Coatings: Challenges, Perspectives, and Opportunities. Trends Biotechnol. 2015;33:637-52.

4. Robertson J. Diamond-like amorphous carbon. Mater Sci Eng: R. 2002;37:129-281.

5. Lackner JM, Waldhauser W. Inorganic PVD and CVD Coatings in Medicine - A Review of Protein and Cell Adhesion on Coated Surfaces. J Adhes Sci Technol. 2010;24:925-96.

6. Hauert R, Thorwarth K, Thorwarth G. An overview on diamondlike carbon coatings in medical applications. Surf Coat Tech. 2013;233:119-30.

7. Harrison JJ, Ceri H, Stremick CA, Turner RJ. Biofilm susceptibility to metal toxicity. Environ Microbiol. 2004;6:1220-7.

8. Hajipour MJ. Antibacterial properties of nanoparticles. Trends Biotechnol. 2012;30:499-511.

9. Maitz MF. Applications of synthetic polymers in clinical medicine. Biosurf and Biotrib. 2015;1:161-76.

10. Praveen S, Rohaizak M. Local Antibiotics are Equivalent to Intravenous Antibiotics in the Prevention of Superficial Wound Infection in Inguinal Hernioplasty. Asian J Surg. 2005;32:59-6.

11. Weltz V, Guldberg R, Lose G. Efficacy and perioperative safety of synthetic mid-urethral slings in obese women with stress urinary incontinence. Int Urogynecol J. 2015;26:641-8.

12. Jirschele K, Seitz M, Zhou Y, Rosenblatt P, Culligan P, Sand P. A multicenter, prospective trial to evaluate mesh-augmented sacrospinous hysteropexy for uterovaginal prolapse. Int Urogynecol J. 2015;26:743-8.

13. Hutan M, Bartko C, Majesky I, Prochotsky A, Sekac J, Skultety J. Reconstruction option of abdominal wounds with large tissue defects. BMC Surgery. 2014;14:50

14. Santo A, Gil DM, Pomiro F, Piro OE, Echeverria GA. Biofilm inhibition by a new $\mathrm{Mn}(\mathrm{II})$ complex with sulfamethoxazole: Synthesis, spectroscopic characterization and crystal structure. Inorg Chim Acta. 2015;436:16-22.

15. Jiang X, Lv B, Shen Q, Wang X. Preparation of silicon-modified antimicrobial polyethylene endotracheal tubes. J Biomed Mater Res Part B Appl Biomater. 2017;105(1):91-98.

16. Wang R, Neoh KG, Kang ET, Tambyah PA, Chiong E. Antifouling coating with controllable and sustained silver release for long-term inhibition of infection and encrustation in urinary catheters. J Biomed Mater Res Part B Appl Biomater. 2015;103:519-28.

17. Gosau M, Haupt M, Thude S, Strowitzki M, Schminke B, Buegers R. Antimicrobial effect and biocompatibility of novel metallic nanocrystalline implant coatings. J Biomed Mater Res Part B App Biomater. 2016;104(8):1571-9.

18. Pereira FDES, Bonatto CC, Lopes CAP, Pereira AL, Silva LP. Use of MALDI-TOF mass spectrometry to analyze the molecular profile of Pseudomonas aeruginosa biofilms grown on glass and plastic surfaces. Microbial Pathogenesis. 2015;86:32-37.

19. Rybtke M, Hultqvist LD, Givskov M, Tolker-Nielsen T. Pseudomonas aeruginosa biofilm infections: community structure, antimi- crobial tolerance and immune response. J Mol Biol. 2015;427(23):3628-45.

20. Veisfeld N, Geller JD. Ion sputtering yield measurements for submicrometer thin films. J Vac Sci Technol A Vac Surf Films. $1988 ; 6: 2077$ 
21. Hudzicki J. Kirby-Bauer Disk Diffusion Susceptibility Test Protocol. ASM MicrobeLibrary. 2013. http://www.microbelibrary. org/component/resource/laboratory-test/3189-kirby-bauer-diskdiffusion-susceptibility-test-protocol. Accessed 15 Sep 2016.

22. Takeno T, Saito H, Goto M, Fontaine J, et al. Deposition, structure and tribological behavior of silver-carbon nanocomposite coatings. Diamond Relat Mater. 2013;39:20-26.

23. Dai W, Wang A. Deposition and properties of Al-containing diamond-like carbon films by a hybrid ion beam sources. J Alloys Compd. 2011;509:4626-31.

24. Wang AY, Lee KR, Ahn JP, Han JH. Structure and mechanical properties of $\mathrm{W}$ incorporated diamond-like carbon films prepared by a hybrid ion beam deposition technique. Carbon. 2006; 44:1826-32.

25. Zhang S, Bui XL, Jiang J, Li X. Microstructure and tribological properties of magnetron sputtered nc-TiC/a-C nanocomposite. Surf Coat Technol. 2005;198:206-11.

26. Rogers HJ, Woods VE, Synge C. Antibacterial effect of the Scandium and Indium complexes of enterochelin on Escherichia coli. J Gen Microbiol. 1982;128:2389-94.

27. Bewilogua K, Cooper CV, Specht C, Schröder J, Witorff R, Grischke M. Effect of target material on deposition and properties of metal-containing DLC (Me-DLC) coatings. Surf Coat Technol. 2000;127:224-32.

28. Lemire JA, Harrison JJ, Turner RJ. Antimicrobial activity of metals: mechanisms, molecular targets and applications. Nat Rev Microbiol. 2013;11:371-84.

29. Barillo DJ, Marx DE. Silver in medicine: A brief history BC 335 to present. Burns. 2014;40:S3-S8.

30. Das A, Kumara A, Patilb NB, Viswanathana C, Ghosh D. Preparation and characterization of silver nanoparticle loadedamorphous hydrogel of carboxymethylcellulose for infected wounds. Carbohyd Polym. 2015;130:254-61.

31. Prabhu S, Poulose EK. Silver nanoparticles: mechanism of antimicrobial action, synthesis, medical applications, and toxicity effects. Int Nano Lett. 2012;2:1-10.

32. Kim JS, Kuk E, Yu KN, Kim Jong-Ho, et al. Antimicrobial effects of silver nanoparticles. Nanomed Nanotech Biol Med. 2007;3:95-101.

33. Schiffmann KI, Fryda M, Goerigk G, Lauer R, Hinze P, Bulack A. Sizes and distances of metal clusters in Au-, Pt-, W- and Fecontaining diamond-like carbon hard coatings: a comparative study by small angle X-ray scattering, wide angle X-ray diffraction, transmission electron microscopy and scanning tunnelling microscopy. Thin Solid Films. 1999;347:60-71.

34. Breuer L, Kucher A, Herder M, Wucher A, Winograd N. Formation of neutral $\mathrm{In}_{\mathrm{m}} \mathrm{C}_{\mathrm{n}}$ clusters under $\mathrm{C}_{60}$ ion bombardment of indium. J Phys Chem A. 2014;118:8542-52.

35. Hu XM, Xue LW, Zhao GQ, Yang WC. Synthesis, structures, and biological activity of Terbium(III) and Cobalt(III) complexes derived from tripodal Schiff bases. Russ J Coord Chem. 2015;41:197-201.

36. Yuoh ACB, Agwara MO, Yufanyi DM, Conde MA, Jagan R, Eyong KO. Synthesis, crystal structure, and antimicrobial properties of a novel 1-D cobalt coordination polymer with dicyanamide and 2-aminopyridine. Int J Inorg Chem. 2015;2015:106838. http://dx.doi.org/10.1155/2015/106838.
37. Singh K, Kumar Y, Puri P, Kumar M, Sharma C. Cobalt, nickel, copper and zinc complexes with 1,3-diphenyl-1H-pyrazole-4carboxaldehyde Schiff bases: Antimicrobial, spectroscopic, thermal and fluorescence studies. Eur J Med Chem. 2012;52: 313-21.

38. Chang EL, Simmers C, Knight DA. Cobalt complexes as antiviral and antibacterial agents. Pharmaceuticals. 2010;3:1711-28.

39. Icgen B, Yilmaz F. Co-occurrence of antibiotic and heavy metal resistance in Kýzýlýrmak river isolates. Bull Environ Contam Toxicol. 2014;93:735-43.

40. Vargas-reusa MA, Memarzadeh K, Huang J, Ren GG, Allaker RP. Antimicrobial activity of nanoparticulate metal oxides against peri-implantitis pathogens. Int $\mathrm{J}$ Antimicrob Agents. 2012; 40:135-9.

41. Bolt AM, Mann KK. Tungsten: an Emerging Toxicant, Alone or in Combination. Curr Envir Health Rpt. 2016;3:405

42. Henry J, Mohanraj K, Sivakumar G, Umamaheswari S. Electrochemical and fluorescence properties of $\mathrm{SnO}_{2}$ thin films and its antibacterial activity. Spectrochim Acta Part A. 2015;143:172-8.

43. Fakhri A, Behrouz S, Pourmand M. Synthesis, photocatalytic and antimicrobial properties of $\mathrm{SnO}_{2}, \mathrm{SnS}_{2}$ and $\mathrm{SnO}_{2} / \mathrm{SnS}_{2}$ nanostructure. J Photochem Photobiol B Biol. 2015;149:45-50.

44. Pop CS, Hussien MD, Popa M, Mares A, et al. Metallic-based micro and nanostructures with antimicrobial activity. Curr Top Med Chem. 2015;15(16):1577-82.

45. Paéz PL, Bazán CM, Bongiovanni ME et al. Oxidative stress and antimicrobial activity of Chromium(III) and Ruthenium(II) complexes on Staphylococcus aureus and Escherichia coli. Biomed Res Int. 2013;2013.

46. Han X, Yan F, Zhang A, Yan P, et al. Structure and tribological behavior of amorphous carbon films implanted with $\mathrm{Cr}^{+}$ions. Mater Sci Eng A. 2003;348:319-26.

47. Jenilek M, Kocourek T, Zemek J, et al. Chromium-doped DLC for implants prepared by laser-magnetron deposition. Mater Sci Eng C. 2015;46:381-6.

48. Singh K, Kumar Y, Puri P, Sharma C, Aneja KR. Antimicrobial, spectral and thermal studies of divalent cobalt, nickel, copper and zinc complexes with triazole Schiff bases. Arab J Chem. 2013;10: S978-S987.

49. Bhaskar R, Salunkhe N, Yaul A, Aswar A. Bivalent transition metal complexes of ONO donor hydrazone ligand: Synthesis, structural characterization and antimicrobial activity. Spectrochim Acta Part A. 2015;151:621-7.

50. Xue L, Deng DN, Xu Y, Wang Q. Synthesis, Crystal Structure, and Antibacterial Activity of a Manganese(III) Complex Derived from N,N'-3,4-Chlorophenylene-Bis(5-Methylsalicylaldimine). Russ J Coord Chem. 2015;41:772-6.

51. Chen Q, Thouas G. Biomaterials: a basic introduction. 1st ed. Boca Raton (FL): CRC Press; 2015.

52. Tsai MT, Chang YY, Huang HL, Chen YC, Wang SP, Lai CH. Reprint of "Biological characteristics of human fetal skin fibroblasts and MG-63 human osteosarcoma cells on tantalum-doped carbon films". Surf Coat Tech. 2014;259:213-8.

53. Dai W, Ke P, Moon MW, Lee KR, Wang A. Investigation of the microstructure, mechanical properties and tribological behaviors of Ti-containing diamond-like carbon films fabricated by a hybrid ion beam method. Thin Solid Films. 2012;520:6057-63. 